\title{
NOTA
}

\section{ANACRAGA CITRINOPSIS DYAR (LEPIDOPTERA: DALCERIDAE) EM MAMONEIRA NO ESTADO DE SÃO PAULO (')}

\author{
ANDRÉ LUIZ LOURENÇĀO $(2,4)$, LUL OLAVO DE CARVALHO (3) \\ e DALMO HENRIQUE DE CAMPOS LASCA (3)
}

A família Dalceridae compreende, em sua maioria, espécies da regiāo neotropical (LIMA, 1945), sendo conhecida apenas uma no Sul dos EUA (5). As lagartas apresentam a superficie dorsal coberta de tubérculos de aspecto gelatinoso ou vitreo; devido a essa característica, espécies dessa familia sāo vulgarmente conhecidas como lagarta-gelatina, lagarta-gelatinosa ou lagarta-de-vidro. No Brasil, săo restritas as citaçōes de ocorrência de dalcerideos causando injúrias em plantas cultivadas; as referências abrangem três gêneros, num total de cinco espécies: (1) Acraga flava (Walker): as lagartas alimentam-se de folhas de goiabeira (Psidium guajava L.) (BIEZANKO, 1961a; BIEZANKO, 1961b); (2) A. melinda (Druce): as lagartas alimentam-se de folhas de goiabeira (BIEZANKO, 1961a; 1961b; MARICONI \& SOUBIHE SOBRINHO, 1961) e de roseira (Rosa sp.) (SILVA et al., 1968); (3) A. moorei Dyar. as lagartas alimentam-se de folhas de cafeeiro (Coffea arabica L.) (SILVA et al., 1968); (4) Dalcera abrasa (Herrich - Schaeffer): as lagartas alimentam-se de folhas de cafeeiro (ARAUJO, 1951; ORLANDO \& RIBEIRO, 1955; SARMENTO, 1958) e (5) Zadalcera fumata Schaus: as lagartas

\footnotetext{
(1) Recebido para publicaçāo em 17 de agosto de 1988 e aceito em 27 de março de 1989. nas, SP.

(2) Seção de Entomologia Fitotécnica, Instituto Agronómico (IAC), Caixa Postal 28, 13001 Campi-

(3) Grupo Técnico de Oreaginosas, Coordenadoria de Assistência Técnica Integral (CATI), Caixa Postal 960, 13001 Campinas, SP.

${ }^{4}$ ) Com bolsa de pesquisa do CNPq.

(5) V.O. BECKER. Informaçăo pessoal, 1988.
} 
alimentam-se de folhas de laranjeira (Citrus sinensis Osbeck) (GOMES \& REINIGER, 1939; BIEZANKO et al., 1949; BIEZANKO, 1961a; 1961b) e de Eucalyptus saligna Sm. (SILVA et al., 1968).

No município de Caiuá, no Oeste paulista, foi observado, em junho de 1982, ataque de uma espécie de lagarta da familia Dalceridae em folhas de mamoneira (Ricinus communis L.) de uma lavoura comercial, apresentando as plantas baixo desfolhamento. Não houve necessidade de aplicação de medidas de controle. No mesmo mês do ano seguinte, observou-se nova incidência dessa lagarta em lavouras dos municípios de Tupi Paulista, Ouro Verde e Marabá Paulista, Oeste do Estado, também causando poucas injúrias às plantas.

Em junho de 1984, constatou-se reduzido ataque em mamoneira IAC 80 de campo de demonstração (um hectare) no município de Cândido Rodrigues, região central do Estado. Nesse mesmo período, ocorreu infestação acentuada da lagarta em campo de demonstração (um hectare) e numa lavoura de quatro alqueires, ambos plantados com IAC 80, em Junqueirópolis, Oeste paulista; nesses locais, houve desfolha mais acentuada, apresentando as folhas sintomas peculiares do ataque (Figura 1A). Verificou-se maior concentração de lagartas na face inferior das folhas localizadas na parte mediana das plantas. Notaram-se geraçōes superpostas no campo, com presença simultânea de ovos, lagartas de diferentes instares (Figura 1B), pupas e adultos. A oviposição se deu preferencialmente na página inferior das folhas, em pequenos grupos, variando de três a quinze, em geral um grupo por fotha, localizado no lobo terminal e próximo ao bordo. Ao final do estádio larval; também na face inferior da folha, a lagarta une, por meio de fios de seda, partes da epiderme foliar que ladeiam seu corpo, formando pequeno sulco onde constrói o casulo, que vai abrigar a pupa. Foram encontradas até seis pupas numa mesma folha, uma em cada lobo. Observou-se a ocorrência de doenças, não identificadas, e de parasitóides nas lagartas, o que controlou provavelmente a infestação, pois a população do inseto regrediu rapidamente nesses locais, sem nenhuma medida de controle.

Lagartas e pupas coletadas em Caiuá, Tupi Paulista, Junqueirópolis e Cândido Rodrigues originaram, em laboratório, adultos de Anacraga citrinopsis Dyar (incorporados à coleção de insetos dáa Seção de Entomologia Fitotécnica do Instituto Agronômico de Campinas, sob os números 6736, 6791, 6830 e 6842 respectivamente) e também parasitóides. Coletas de Ouro Verde deram origem apenas a parasitóides. $O$ estudo desse grupo de himenópteros revelou a ocorrência de três espécies pertencentes a três familias distintas (SANTIS, 1987): Glyptapanteles dalosoma Santis, 1987 (Hymenoptera: Braconidae); Isdromas monterai (Costa Lima, 1948) (Hymenoptera: Ichneumonidae), provavelmente parasitóide de G. dalosoma e Ceratosmicra argentina Blanchard, 1942 (Hymenoptera: Chalcididae), parasitóide de outros himenópteros das famílias Braconidae e Ichneumonidae e que se pode ter comportado como hiperparasitóide de segundo ou terceiro grau. 

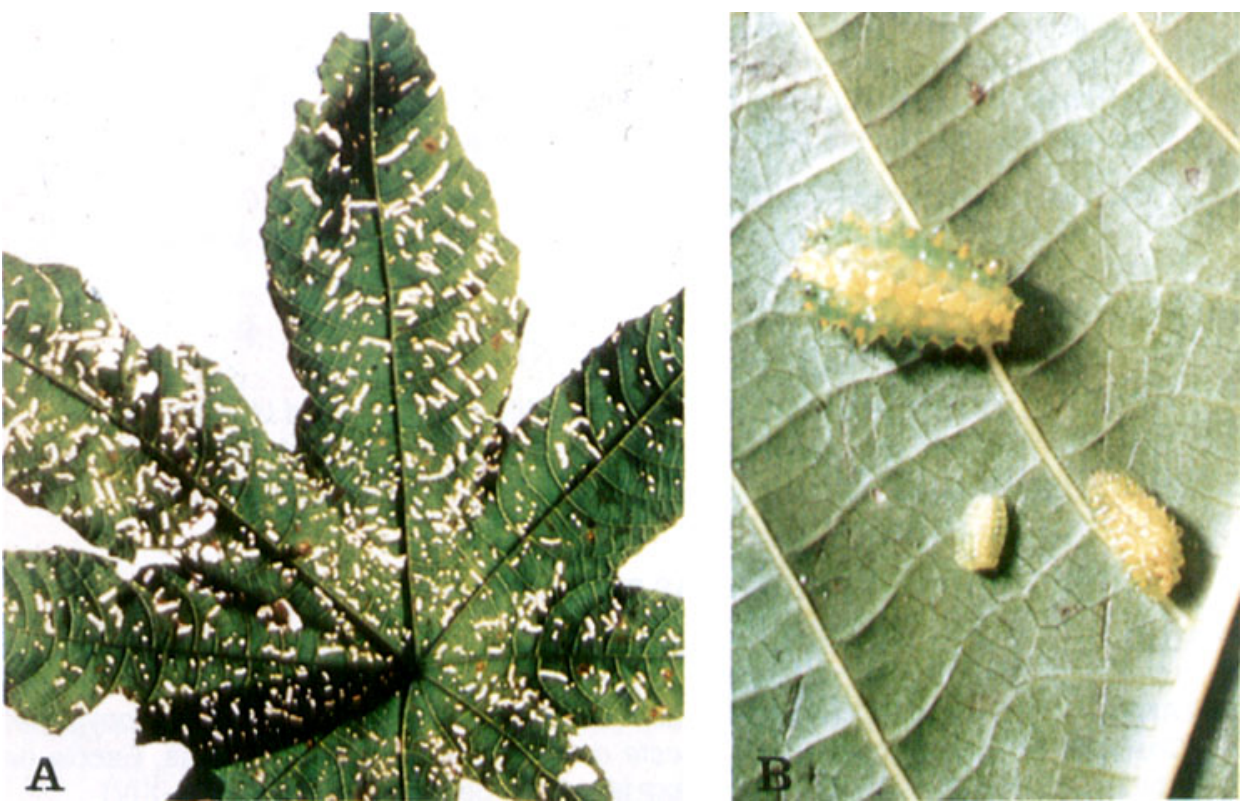

FIGURA 1. Anacraga citrinopsis Dyar. A: injúrias em folha de mamoneira causadas pela alimentação de lagartas; B: lagartas de diferentes estádios. Junqueirópolis, SP, 1984.

Até o momento, não se conhece, no Brasil, nenhum dalcerídeo considerado praga de alguma planta cultivada. No caso de $A$. citrinopsis, apenas em 1984 verificou-se a ocorrência de infestação mais intensa, não tendo havido, contudo, necessidade de controle. Nos anos seguintes, não foram observadas novas infestaçōes desse inseto dignas de registro.

Termos de indexação: Anacraga citrinopsis Dyar; mamoneira, Ricinus communis L.; Ceratosmicra argentina Blanchard, Glyptapanteles dalosoma Santis, Isdromas monterai (Costa Lima).

\section{SUMMARY}

ANACRAGA CITRINOPSIS DYAR (LEPIDOPTERA: DALCERIDAE) ON CASTOR-BEAN PLANT IN THE STATE OF SĀO PAULO, BRAZIL

Larvae of $A$. citrinopsis Dyar were found feeding on leaves of castor-bean plants (Ricinus communis L.) on plantations at Caiuá, Tupi Paulista, Junqueirópolis, Ouro Verde, Marabá Paulista and Cândido Rodrigues, in the State of Săo Paulo, Brazil. The larvae feed on the lower surface of leaves, were they form cocoon and pupate later on. Only at Junqueirópolis the infestation was high, but there was a natural decrease in the insect 
population. The hymenopterous Glyptapanteles dalosoma Santis, 1987 (Braconidae), Ceratosmicra argentina Blanchard, 1942 (Chalcididae) and Isdromas monterai (Costa Lima, 1948) (Ichneumonidae) were reared from larvae; the latter two probably behaved as hyperparasites.

Index terms: Anacraga citrinopsis Dyar, castor-bean, Ricinus communis L., Ceratosmicra argentina Blanchard, Glyptapanteles dalosoma Santis, Isdromas monterai (Costa Lima).

\section{AGRADECIMENTOS}

Os autores agradecem ao Dr. Scott Miller, da Harvard University, EUA, e ao Dr. Vitor O. Becker, do Centro de Pesquisa Agropecuária dos Cerrados, EMBRAPA, a identificação do inseto.

\section{REFERÊNCIAS BIBLIOGRÁFICAS}

ARAUJO, R.L. Dados bionômicos de uma lagarta do cafeeiro Dalcera abrasa Herr.-Sch. 1854 (Lep., Dalceric ae). O Biológico, São Paulo, 17(3):55-57, 1951.

BIEZANKO, C.M. de. Castniidae, Zygaenidae, Dalceridae, Eucleidae, Megalopygidae, Cossidae et Hepialidae da Zona Sueste do Rio Grande do Sul. Pelotas, Escola de Agronomia "Eliseu Maciel", 1961a. 6p. (Arquivos de Entomologia, série A-XIV)

- Castniidae, Zygaenidae, Dalceridae, Eucleidae, Megalopygidae, Cossidae et Hepialidae da Zona Missioneira do Rio Grande do Sul. Pelotas, Escola de Agronomia "Eliseu Maciel", 1961b. 8p. (Arquivos de Entomologia, série B-XIV)

-; BERTHOLDT, R.E. \& BAUCKE, O. Relação dos principais insetos prejudiciais observados nos arredores de Pelotas nas plantas cultivadas e selvagens. Agros, 2(3):156-213, 1949.

GOMES, J.G. \& REINIGER, C.H. Nota prévia sobre uma nova praga da laranjeira. Revista da Sociedade Brasileira de Agronomia, Rio de Janeiro, 2:26, 1939.

LIMA, A. da C. Insetos do Brasil: Lepidópteros. Rio de Janeiro, Escola Nacional de Agronomia, 1945. tomo 5, p.180-186. (Série didática, 12)

MARICONI, F.A.M, \& SOUBIHE SOBRINHO, J. Contribuição para o conhecimento de atguns insetos que depredam a goiabeira (Psidium guajava L.). Piracicaba, Escola Superior de Agricultura "Luiz de Queiroz", Instituto de Genética, 1961. p.35-67. (Publicação cientifica, 2)

ORLANDO, A. \& RIBEIRO, B.L. Ensaios preliminares de controle à "lagarta gelatinosa" dos cafezais, por meio de polvilhamento. O Biológico, São Paulo, 21(8):140-146, 1955.

SANTIS, L. de. Himenópteros parasitóides e hiperparasitóides de Anacraga sp. (Lepidoptera, Dalceridae) en Brasil. Revista Brasileira de Entomotogia, 31(1):97-99, 1987.

SARMENTO, A.A. Lagartas prejudiciais às nossas plantas cultivadas. Boletim de Agricultura, Belo Horizonte, 7(11/12):13-26, 1958.

SILVA, A.G. d'A. e; GONÇALVES, C.R.; GALVĀO, D.M.; GONÇALVES, A.J.L.; GOMES, J.; SILVA, M. do N. \& SIMONI, L. de. Quarto catálogo dos insetos que vivem nas plantas do Brasil, seus parasitos e predadores. Rio de Janeiro, Ministério da Agricultura, Departamento de Defesa e Inspeção Agropecuária, 1968. parte 2, tomo 1, p.295-296. 